\title{
Psychological Aspects of Rape and Its Consequences
}

\author{
Suprakash Chaudhury ${ }^{1 *}$, Ajay Kumar Bakhla ${ }^{2}$, P.S. Murthy ${ }^{3}$ and Biswajit Jagtap ${ }^{4}$ \\ ${ }^{1}$ Dept of Psychiatry, Rural Medical College, India \\ ${ }^{2}$ Dept of Psychiatry, RIMS, Ranchi, India \\ ${ }^{3}$ Dept of Psychiatry, Santhiram Medical College \& General Hospital, India \\ ${ }^{4}$ Dept of Psychiatry, Rural Medical College, India
}

Submission: February 06, 2017; Published: March 10, 2017

*Corresponding author: Suprakash Chaudhury, Dept of Psychiatry, Rural Medical College, Pravara Institute of Medical Sciences, (DU) Loni Dist. Ahmednagar, Maharashtra, India, Tel: 919370386496; Email: suprakashch@gmail.com

\begin{abstract}
Sexual contact without voluntary consent that violates a person's sense of autonomy, control and mastery over their body constitutes sexual assault. It is increasingly recognized that many patients in primary settings have a history of sexual abuse. Demographics of sexual violence are usually obtained from crime records, hospital data, nongovernmental organizations and survey carried out for research. It is believed that these data underestimate the actual magnitude of the problem of sexual violence. In this paper we review the psychological aspects of rape and its consequences including rape trauma syndrome, posttraumatic stress disorder, depression, anxiety, sleep disorders, memory and sexuality. Further research is necessary to better understand the pathogenesis of psychiatric disorders in survivors of sexual assault. Research is also needed to determine evidence based management of survivors of sexual abuse coping with long-term mental health outcomes.
\end{abstract}

Keywords: Sexual Trauma; Rape victim; Childhood Sexual abuse

Abbreviations: PTSD: Post-Traumatic Stress Disorder; RMA: Rape Myth Acceptance Scale; HPA: Hypothalamic-Pituitary-Adrenal; CRH: Corticotropin Releasing Hormone; RTS: Rape Trauma Syndrome

\section{Introduction}

Sexual violence is defined as "Any sexual act, attempt to obtain a sexual act, unwanted sexual comments or advances, or acts to traffic, or otherwise directed, against a person's sexuality using coercion, by any person regardless of their relationship to the victim, in any setting, including but not limited to home and work" [1]. Sexual assault is any form of sexual contact without voluntary consent and that violates a person's sense of autonomy, control and mastery over their body. Unwanted sexual experiences are often measured along a continuum, including categories of unwanted sexual contact (e.g., kissing or fondling), verbal coercion, attempted rape, and rape, presumed to reflect the least to most severe experiences. Different methods of coercion: arguments and pressure, misuse of authority, alcohol or drug intoxication (separate questions for attempted and completed acts), and physical force used by the perpetrator has been conceptualized to vary in extent of trauma perceived [2]. Another distinction was attempted on the basis of forcible and incapacitated rape. In forcible rapes more force is used by the perpetrator due to which more resistance is offered by the victim resulting in more injuries [3]. During forcible rapes the victim shows more physical symptoms of stress including shortness of breath, rapid heart rate, and sweating, than during incapacitated rapes [4]. While forcible and incapacitated rapes differ in the degree of physical trauma involved, they may not differ with regard to emotional trauma. Based on these severities and distinctions the psychological consequences may vary [5].

\section{The Extent of the Problem}

Demographics of sexual violence are usually obtained from crime records, hospital data, nongovernmental organizations and survey carried out for research. Some researchers believe that these data underestimate the actual magnitude of the problem of sexual violence. Researchers in western world estimate that only $16-33 \%$ of rapes are reported $[6,7]$. In Indian 
context the situation may be worse. According to the National Crime Records Bureau, 34,651 rape cases were registered in India in 2015, although experts agree that the unreported cases of sexual assault are much higher [8,9].

Studies have established that many patients seen in primary medical care have a history of sexual abuse. Prevalence rates of sexual abuse vary from $4.0 \%$ to $21.4 \%$ in adults and from $3.0 \%$ to $33.2 \%$ in children in the general population $[10,11]$. Therefore it is not surprising that survivors of sexual abuse constitute about $13 \%-26 \%$ of primary care population [12]. Due to the frequent underreporting of sexual abuse these statistics are likely to be underestimates [13]. Recently, several systematic reviews have summarized data from studies of sexual abuse $[14,15]$. These reviews have reported an association between sexual abuse and depression, posttraumatic stress disorder (PTSD), eating disorders, and suicide attempts, but inclusion of cross-sectional studies limits the inferences drawn from the results.

\section{Psychology of Rape}

Five types of rapists or contexts of rape have been proposed [16]:

(a) Disadvantaged men who resort to rape,

(b) "Specialized" rapists who are sexually aroused by violent sex,

(c) Men who rape opportunistically,

(d) high-mating-effort men who are dominant and often psychopathic, and

(e) Partner rapists motivated by assessments of increased risk of sperm competition.

It has been proposed by some researchers that rape is a conditional strategy that may potentially be deployed by any man $[16,17]$. Others have argued that men use a conditional mating strategy consisting of many mating tactics, including rape [18]. In one study one-third of men agreed that they would rape under certain conditions while many reported coercive sexual fantasies [19].

\section{Women's Defenses against Rape}

Rape and sexual violence frequently results in many negative consequences for women. Consequently psychological mechanisms to motivate rape-avoidance behaviors in women have evolved. rape is traumatic for women due to fear of serious physical injury or death, and disruption of a woman's parental care as a result of which the woman's partner may abandons her $[17,20]$. The greatest cost to rape survivors is the circumvention of their mate choice that can severely jeopardize their reproductive success [21].

Cognitive distortions: Self- Blame, self- citicism, helplessness, hopelessness preoccupation and danger are the usual pattern by which victim blames herself for negative, unwanted events (not specifically sexual victimization). Helplessness implies the perception of inability to control important aspects of one's life resulting in passivity in the face of danger. The hopelessness and preoccupation with danger involves beliefs that the world, especially interpersonal relationship, is dangerous. Victims perceive objectively benign circumstances to be risky [22].

Myths causing unfair impact on victim's credibility: Rape myths are specific beliefs surrounding rape, an example of such beliefs is that women enjoy being raped or that they could easily resist rapists if they really wanted to. A myth of "nothing happened" or a false accusation may impact the reporting by victim specially if the assailant is close relative or if there is no eye witness to the assault. Another myth may be "no harm done" that can be interpreted wrongly when victim did not resisted physically, or there is no evidence of physical injury or the assailant used a weapon to threaten the victim. This makes the victim feel that their assault was not serious enough to report and a regret for not fighting back. Another myth is that may be "she wanted it or liked it" usually in context of known or acquaintance assailant [23]. "The Rape Myth Acceptance Scale (RMA)" assesses such beliefs and accepting attitude toward rape [24]. There are other scales like the Acceptance of Interpersonal Violence Scale, to measure the extent to which force and coercion are acceptable in intimate and sexual relationships and the Adversarial Sex Beliefs Scale which has set of scales that correlate highly with the RMA.

\section{Psychological Effects on the Victim}

Emotional and Psychological Consequences of Rape: Sexual violence is associated with numerous acute and chronic sequelae. Rape may result in vaginal or rectal injury, sexuallytransmitted infections, and pregnancy. In the immediate aftermath of a sexual assault, the survivor may report a variety of psychological responses, including acute stress reactions, emotional detachment, and sleep disturbances [25]. Other adverse emotional and psychological consequences include self-blame, difficulties in social and work adjustment and sexual functioning, fear, anxiety, depression, and PTSD [26-29].

The psychological consequences of sexual trauma among survivors have been widely studied. The National Violence against Women Survey reported that $18 \%$ of women experienced a completed or attempted rape during their lifetime [30]. Majority (54\%) of the rape survivors were less than 18 years old when they experienced their first attempted or completed rape. The response of survivors to the trauma of rape are complex and unique [31]. While some rape survivors suffer from severe symptoms or long-term distress, others do not [32]. The difference in outcomes is explained by survivor attributes, environmental conditions, type of violence perpetrated and resulting injuries, availability of social support and resources. 
While some individuals may be resilient to the negative effects of sexual trauma, for other women sexual victimization is the most devastating event that they will experience. In a comprehensive systematic review and meta-analysis of 37 longitudinal observational comparative studies including $3,162,318$ participants found an association between a history of sexual abuse and a lifetime diagnosis of anxiety, depression, eating disorders, PTSD, sleep disorders, and suicide attempts, but not with schizophrenia or somatoform disorders. A history of rape strengthened the associations between history of sexual abuse and depression, eating disorders, and PTSD [33]. Similarly an association between childhood maltreatment and anxiety, depression, eating disorders, PTSD, sleep disorders and suicide attempts was reported in a systematic review of longitudinal studies of childhood maltreatment and mental health outcomes between 2000 and 2008 found [34].

Following the sexual assault the survivor may develop dysregulation of the hypothalamic-pituitary-adrenal (HPA) axis. The HPA axis is a key regulator of function in the body, controlling neural, endocrine and immune systems through negative feedback inhibition. Cortisol, the primary stress hormone in the body, is a major hormone of the HPA axis. The release of cortisol is stimulated by Corticotropin Releasing Hormone (CRH) and inhibited by negative feedback on the hypothalamus and pituitary gland. Severe psychological trauma such as rape and sexual abuse changes the body's response to stress by increasing levels of CRH and dysregulating the HPA axis. Inappropriate fear reactions and persistent mild depression can result from dysregulation of cortisol [35].

In addition to anxiety and depression, psychological adverse effects of a sexual assault include intense feelings of shame and guilt [36]. These feelings are worsened by the lack of support from family, friends or authorities. Following sexual assault feelings of mental confusion and defeat, negative appraisal of symptoms and emotions, avoidance and perception of negative responses from others are some of the cognitive factors that play a large role in the onset, severity, and outcome of PTSD. The risk of PTSD is greater if the rape survivor believes that others have failed to react in a positive and supportive manner [36].

Events perceived as controllable are much less distressing than uncontrollable events. Consequently after the occurrence of uncontrollable events such as sexual assault, survivors tend to attribute blame to behavioral, dispositional or vicarious causes [37] Behavioral self blame has the potential to be adaptive as it promotes the belief that negative outcomes can be avoided in the future; whereas dispositional self-blame attributes the traumatic event to one's personality and this thinking does not give a sense of future control. Vicarious control refers to the perception that some other person controlled the occurrence of that event [37]. Attributing blame in these ways is associated with poorer outcomes in PTSD. In view of the fact that control over the recovery process results in lowered distress levels, fostering this form of control could be an important component of interventions for sexual assault survivors.

Recovery from sexual- assault is not solely measured by eliminating symptoms or achieving specific outcomes. Rather, successful recovery is subjective and measured by whether the survivor increases his or her involvement in the present, acquires skills and attitudes to regain control of his of her life, forgive him or herself for guilt, shame and other negative cognitions, and gain stress reduction skills for overall better functioning. The degree of support received, premorbid self-concept, personal strength, adequate treatment provided by professional and appropriate legal remedy by the justice systems are all important factors for successful recovery [38].

\section{Factors affecting Impact and outcome of Rape: Age of Rape Victims}

Age of the rape or sexual offence victim is one of the most influential factor that may determines the impact and consequences of the offence. The children are developmentally immature and also susceptible for the sexual offence. The overall long term consequences depends heavily on frequency and duration of victimization [39], whereas supportive family environment [40] specially supportive and protective maternal responses may be important issue in recovery with better outcome psychologically and functioning among survivors [41]. Survivors of childhood sexual abuse are at five times more risk to develop PTSD [12], and much higher incidence of depression, suicide, and other psychological problems. Among survivors of childhood rape the rate of lifetime depression was $52 \%$ compared to $27 \%$ among non-victims [42]. Childhood sexual abuse is found to be associated with increased risk of suicidal attempt, [43] alcohol abuse [44] and eating disorders [45] later in life.

\section{Rape Trauma Syndrome (RTS)}

Although every rape survivor is unique, many will have one thing in common: RTS. RTS is a cluster of emotional responses to the extreme stress experienced and profound fear of death experienced by the survivor during the sexual assault. RTS is characterized by three phases.

A. The Acute (Initial) Phase occurs immediately after the assault and lasts from a few days to a few weeks. During the sexual assault the survivor commonly experiences an intense fear of death and dissociation. These are natural physical responses. Being paralyzed by fear does not mean the survivor gave consent or desired the assault. Even if the victim/survivor "decides" that it is safest not to physically resist in the situation, this does not mean she wanted it to happen or gave consent. Immediately following the assault the survivor is in crisis and experiences a wide range of emotional reactions categorized as 'Expressive', such as shaking, crying or yelling; or 'Controlled' such as flattened affect, appearing outwardly calm and subdued. 
Research indicates that anxiety and intense fear are the primary responses following rape which peaks at around three weeks after the rape but can last for more than a year [46]. Ongoing fears can be related to reminders of the attack (e.g., legal proceedings or medical examinations, being with men, or being in a location that reminds the person of the assault). Fears of future attacks, fear of contracting HIV/STIs and/or becoming pregnant is common [47]. Survivor who had previously experienced the world as basically a safe place may now believe the world to be inherently untrustworthy and unsafe leading to the restriction of social activities, including work and community involvement [48]. For some women, particularly those from marginalized communities, sexual assault can reaffirm assumptions about themselves as devalued persons ("insidious trauma"), and about the world being unsafe and dangerous [49].

B. The second phase is 'Outward Adjustment' during which the survivor focuses less on the assault, often with a high level of denial, and involves themselves in normal daily activities.

c. The final phase is 'Long Term Reorganization' during which the survivor integrates the assault into their view of themselves and resolves their feelings about the assailant. The Reorganization Phase may last anywhere from a few weeks to several years after the attack.

\section{Medium-to-long-term Psychological Impacts}

Research suggests victim/survivors may experience a range of medium-to-long-term impacts, like feelings of low self-esteem, self-blame and guilt can endure for months and years after the assault. Commonly survivors forget or deny aspects of their experience which can be a defense against overwhelming feelings of confusion, shock and bewilderment. This may be especially powerful in partner rape [48]. A systemic review and meta analysis of literature of 28 years concluded that survivors of sexual abuse are commonly encountered in general medical practice [33]. Sexual abuse was associated with multiple psychiatric disorders, including lifetime anxiety disorders, depression, eating disorders, PTSD, sleeps disorders, and attempted suicide. Further research is needed to improve our understanding of the pathogenesis of psychiatric disorders to improve their treatment in survivors of sexual assault [33].

Suicidal ideation is more common among survivors of sexual assault than the general population [50]. Younger survivors are at particular risk of attempting suicide following rape [51]. Trauma and post-traumatic stress disorder (PTSD) The trauma response model and clinical diagnosis of post-traumatic stress disorder (PTSD) has helped to acknowledge the significance of the harm caused to people who have been sexually assaulted, and the extent of the violation they have experienced.

While rape will always be a traumatic experience, the effects of this trauma for an individual may differ in different contexts. Some trauma measures reflect dominant views about the world that many people do not share. Certain symptoms of trauma, rather than being viewed as problems to be treated, need to be viewed in a more positive light—-that is, as "coping mechanisms" an individual has adopted for protection and other purposes [52]. Symptoms of PTSD (which can persist for 3 years or more) include: intrusive thoughts and distressing recollections of the violence; nightmares and other sleep disturbances; and depression. Women survivors of sexual violence may constitute the single largest group of people affected by PTSD [47]. One study reported a $43 \%$ prevalence rate of depression among women who had experienced sexual violence. [51]Another study observed that $39 \%$ of women with a sexual assault history met criteria for a mood or anxiety disorder; and avoidance behaviors [53].

Common long-term psychological and social effects of sexual violence include depression, chronic posttraumatic stress symptoms, interpersonal disturbances and revictimization $[11,54,55]$. In addition, sexual violence is associated with lingering negative health repercussions that include gastrointestinal distress, chronic pelvic pain, health risk behaviors, substance abuse, and high utilization of health care services [56,57].

A. Sexual trauma and memory: All autobiographical experiences and memories related to sexual trauma can be failed, confabulated, or incompletely recalled [58] with various psychological processes like dissociation, [59]amnesia, [60] repression, [61] and ordinary or motivated forgetting [62]. These phenomenons may be important clinically and legally. Sexual trauma and its recall deficits are associated with decreased perception of life threat as in the cases of acquaintance rape in familiar situations, in contrast to stranger rapes [63].

B. Trauma-Related Sleep Disturbance: Assessment of 167 rape and trauma victims for PTSD symptoms, depression, sleep disturbance, and frequency of self-reported health symptoms revealed that trauma-related sleep disturbance predicted unique variance in physical health symptoms after other PTSD and depression symptoms were controlled. This finding indicates that trauma-related sleep disturbance contributes to physical health symptoms in rape survivors with PTSD [64]. The most enduring symptoms of sleep disturbances in sexually abused are nightmare related distress, sleep paralysis, nightly awakenings, restless sleep, and tiredness [57].

C. Post Traumatic Stress Disorder (PTSD): Rape is a significant trauma that leads to short term and long term stress reaction and victims are at significantly increased risk of developing PTSD [65]. Nearly one-third to $50 \%$ of all rape victims develops Rape-related PTSD (RR PTSD) sometime during their lifetimes $[66,67]$. The four major symptoms of RR PTSD are re-experiencing the trauma or intrusive thoughts, social withdrawal, avoidance behaviors and actions and increased physiological arousal characteristics. However, in most of the people PTSD symptoms diminish over time. One study found RR PTSD in $94 \%$ of the rape victims, within one week of the rape, which reduced to $47 \%$ after three months [29]. 
D. Other symptoms: Rape survivors exhibit depression, fear and anxiety, problems with social and work adjustment, and problems with sexual functioning subsequent to their assault. Reported rates of depression range from $68-74 \%$ in the first four weeks post sexual assault, but diminish to normal levels within a few months in the majority of victims [68]. The comorbid relationship between PTSD, depression and anxiety was examined in 126 women during the first four weeks postsexual assault. This prospective investigation highlighted the role of PTSD symptoms in influencing subsequent change in other psychological symptoms [69].

E. Resilience and recovery: Survivors possess significant resilience in the face of these negative impacts and the negative reactions of others. Resilience and healing for victim/survivors are multidimensional processes; survivors are both "suffering and surviving" [70]. Resilience and healing is promoted by the following: positive reactions of support (empathy, belief, understanding); speaking out about sexual assault; social acknowledgement of the impacts of sexual assault; and strong, empathetic social networks [71].

Mental health consequences also depend on the manner in which the survivors mentally process their experiences of sexual trauma [72]. Background characteristics influence the severity of self-blaming thoughts, which predicts the degree of maladaptive beliefs that survivors use to understand and interpret adverse life experiences. Maladaptive beliefs may be a better predictor of psychological distress than assault characteristics [73]. Survivors' perceptions of past control (i.e., control over the assault), present control (i.e., control over recovery process) and future control (i.e., control over future victimizations) are related to posttrauma distress. Survivors who strongly perceived that they had control over their recovery process were less distressed [74].

F. Impact of Rape on Female Sexuality: Compared to nonraped women, survivors of sexual assault show relatively high rates of genital injuries and moderate rates of sexually transmitted infections and significantly greater difficulties with sexual functioning, including dyspareunia, endometriosis, menstrual irregularities, and chronic pelvic pain. Raped women also engaged in significantly more high-risk sexual behaviors. PTSD emerged as an important mediator of sexual victimization and sexual health [75]. The interrelationships among the physical, psychological, biologic, and behavioral factors play a central role in development of negative impact. Each factor, singly, may not be enough to occasion longer term difficulties in sexual health, but the influence of the multiple interacting factors provides collective challenges to bodily systems [76].

\section{Conclusion}

Survivors of sexual abuse suffer numerous psychological effects along with a spectrum of physical and psychiatric disorders resulting in higher health care use. Review of the literature indicates that sexual assault is associated with multiple psychiatric disorders, including anxiety disorders, depression, PTSD, eating disorders, sleep disorders, and deliberate selfharm. Survivors experience diverse negative impacts of sexual assault; there is no list of typical "symptoms" they should exhibit. Such impacts affect not only the physical and mental health of survivors but also their interpersonal relationships with family, friends, partners, colleagues and so on. Further research is necessary to better understand the pathogenesis of psychiatric disorders in survivors of sexual assault. Research is also needed to determine evidence based management of survivors of sexual abuse coping with long-term mental health outcomes.

\section{References}

1. Jewkes R, Sen P, García-Moreno C (2002) Sexual violence. World Report on Violence and Health. World Health Organisation, Geneva.

2. Rose DS (1986) Worse than Death: Psychodynamics of Rape Victims and the Need for Psychotherapy. Am J Psychiatry 43(7): 817-824.

3. Abbey A, BeShears R, Clinton-Sherrod AM, McAuslan P (2004) Similarities and differences in women's sexual assault experiences based on tactics used by the perpetrator. Psychol Women Q 28(4): 323-332.

4. Clum GA, Nishith P, Calhoun KS (2002) A preliminary investigation of alcohol use during trauma and peritraumatic reactions in female sexual assault victims. J Trauma Stress 15(4): 321-328.

5. Koss MP, Abbey A, Campbell R, Cook S, Norris J, et al. (2007) Revising the SES: A collaborativeprocess to improve assessment of sexual aggression and victimization. Psychol Women Q 31(4): 357-370.

6. Greenfield LA (1997) Sex Offenses and Offenders An Analysis of Data on Rape and Sexual Assault, US Department of Justice, Washington, 1-37.

7. Kilpatrick DG, Edmunds C, Seymour A (1992) Rape in America: A report to the nation. Charleston, SC: National Victim Center \& the Crime Victims Research and Treatment Center, Medical University of South Carolina.

8. National Crime Records Bureau (2015) Crime in India 2015 statistics. Ministry of Home Affairs, New Delhi 81-92.

9. Ganguly M (2012) South Asia director “India: Rape Victim's Death Demands Action. Human Rights Watch". Hrw.org. Retrieved 2016-0315.

10. Molnar BE, Buka SL, Kessler RC (2001) Child sexual abuse and subsequent psychopathology: results from the National Comorbidity survey. Am J Public Health 91(5): 753-760.

11. Dube SR, Anda RF, Whitfield CL, Brown DW, Felitti VJ, et al. (2005) Long-term consequences of childhood sexual abuse by gender of victim. Am J Prev Med 28(5): 430-438.

12. Coid J, Petruckevitch A, Chung WS, Richardson J, Moorey S, et al. (2003) Abusive experiences and psychiatric morbidity in women primary care attenders. Br J Psychiatry 183: 332-339.

13. Priebe G, Svedin CG (2008) Child sexual abuse is largely hidden from the adult society An epidemiological study of adolescents' disclosures. Child Abuse Negl 32(12): 1095-1108.

14. Gilbert R, Spatz Widom C, Browne K, Fergusson D, Webb E, et al. (2009) Burden and consequences of child maltreatment in high-income countries. Lancet 373(9657): 68-81.

15. Paolucci EO, Genuis ML, Violato C (2001) A meta-analysis of the published research on the effects of child sexual abuse. J Psychol 135(1): 17-36. 
16. McKibbin WF, Shackelford TK, Goetz AT, Starratt VG (2008) Why Do Men Rape? An Evolutionary Psychological Perspective. Rev Gen Psychol 12(1): 86-97.

17. Thornhill R, Palmer CP (2000) A natural history of rape. Cambridge, MA: The MIT Press.

18. Shields WM, Shields LM (1983) Forcible rape: An evolutionary perspective. Ethol Sociobiol 4(3): 115-136.

19. Malamuth NM, Huppin M, Paul B (2005) Sexual coercion. The handbook of evolutionary psychology, Wiley, pp. 394-418.

20. Shackelford TK (2002) Are young women the special targets of rapemurder? Aggress Behav 28(3): 224-232.

21. Symons D (1979) The evolution of human sexuality. New York: Oxford University Press.

22. Drieschner K, Lange A (1999) A review of cognitive factors in the etiology of rape: Theories, empirical studies and implications. Clin Psychol Rev 19 (1): 57-77.

23. Burt MR (1991) Rape Myths and Acquaintance Rape. In Acquaintance Rape: The hidden crime, edited by Andrea Parrot and Laurie Bechhofer, Hoboken, NJ, US, John Wiley \& Sons, Inc.

24. Burt MR (1980) Cultural myths and support for rape. J Pers Soc Psychol 38(2): 217- 230 .

25. Centers for Disease Control and Prevention (2007) Understanding sexual violence: Fact Sheet.

26. Campbell R, Dworkin E, Cabral G (2009) An ecological model of the impact of sexual health on women's mental health. Trauma Violence Abuse 10(3): 225-246.

27. Campbell R, Wasco SM (2005) Understanding rape and sexual assault: 20 years of progress and future directions. J Interpers Violence 20(1): 127-131.

28. Elliott DM, Mok DS, Briere J (2004) Adult sexual assault: Prevalence, symptomatology, and sex differences in the general population. J Trauma Stress 17(3): 203-211.

29. Rothbaum B, Foa E, Riggs D, Murdock T, Walsh W (1992) A Prospective Examination of Post-traumatic Stress Disorder in Rape Victims. J Trauma Stress 60: 748-756.

30. Tjaden P, Thoennes N (2000) Extent, Nature, and Consequences of Intimate Partner Violence. Findings From the National Violence Against Women Survey. NIJ, Washington 1-55.

31. Briere J, Jordan CE (2004) Violence against women: Outcome complexity and implications for treatment. J Interpers Violence 19(11): 1252-1276.

32. Kendall Tackett KA, Williams LM, Finkelhor D (1993) Impact of sexual abuse on children: A review and synthesis of recent empirical studies. Psychol Bull 113(1): 164-180.

33. Chen LP, Murad MH, Paras ML, Colbenson KM, Sattler AL, et al. (2010) Sexual abuse and lifetime diagnosis of psychiatric disorders: systematic review and meta-analysis. Mayo Clin Proc 85(7): 618-629.

34. Gilbert R, Spatz Widom C, Browne K, Fergusson D, Webb E, et al. (2009) Burden and consequences of child maltreatment in high-income countries. Lancet 373(9657): 68-81.

35. Chivers Wilson KA (2006) Sexual assault and posttraumatic stress disorder: A review of the biological, psychological and sociological factors and treatments. McGill J Med 9(2): 111-118.

36. NCPTSD (2005) National Center for Post Traumatic Stress Disorder. Epidemiological Facts About PTSD - A National Center for PTSD Fact Sheet.
37. Frazier PA (2003) Perceived Control and Distress Following Sexual Assault: A Longitudinal Test of a New Model. J Pers Soc Psychol 84(6): 1257-1269.

38. Matsakis A (1996) I Can't Get Over It: Handbook for Trauma Survivors. Oakland, California: New Harbinger Publications.

39. Steel J, Sanna L, Hammond B, Whipple J, Cross H (2004) Psychological sequelae of childhood sexual abuse: abuse-related characteristics, coping strategies, and attributional style. Child Abuse Negl 28(7): 785801.

40. Fassler IR, Amodeo M, Griffin ML, Clay IR, Ellis MA (2005) Predicting long-term outcomes for women sexually abused in childhood: Contribution of abuse severity versus family environment. Child Abuse Negl 29(3): 269-284.

41. Lovett J, Regan L, Kelly L (2004) Sexual Assault Referral Centres: Developing Good Practice and Maximising Potentials.

42. Saunders Benjamin E, Kilpatrick Dean G, Hanson Rochelle F, Resnick Heidi S, Walker Michael E (1999) Prevalence, Case Characteristics, and Long-Term Psychological Correlates of Child Rape among Women: A National Survey. Child Maltreatment 4(3): 187-200.

43. Stratham DJ, Heath AC, Madden PAF, Bucholz KK, Beirut L, et al. (1998) Suicidal behavior: An epidemiological and genetic study. Psychol Med 28(4): 839-855.

44. Galaif ER, Stein JA, Newcomb MD, Bernstein DP (2001) Gender differences in the prediction of problem alcohol use in adulthood: Exploring the influence of family factors and childhood maltreatment. J Stud Alcohol 62(4): 486-493.

45. Wonderlich, SA Wonderlich, RD Crosby , JE Mitchell , KM Thompson, et al. (2001) Eating Disturbance and Sexual Trauma in Childhood and Adulthood. Int J Eat Disord 30(4): 401-412.

46. Petrak J (2002) The trauma of sexual assault: Treatment, prevention and practice. West Sussex: John Wiley \& Sons, pp 372.

47. Astbury J (2006) Services for victim/survivors of sexual assault: Identifying needs, interventions and provision of services in Australia. ACSSA 6.

48. Crome SA, McCabe MP (1995) The impact of rape on individual, interpersonal and family functioning. J Fam Stud 1(1): 58-70.

49. Wasco SM (2003) Conceptualizing the Harm done by Rape: Applications of Trauma Theory to Experiences of Sexual Assault. Trauma Violence Abuse 4(4): 309-322.

50. Stepakoff S (1998) Effects of sexual victimization on suicidal ideation and behaviour in U.S. college women. Suicide Life Threat Behav 28(1): 107-126.

51. Petrak J (2002) The trauma of sexual assault: Treatment, prevention and practice. West Sussex: John Wiley \& Sons.

52. Morrison ZA, Quadra, Morrison AR, M Ellsberg, S Bott (2007) Addressing gender-based violence: a critical review of interventions. World Bank Res Obser 22(1): 25-51.

53. Littleton H, Breitkopf CR (2006) Coping with the experience of rape. Psychol Women Q 30(1): 106-116.

54. Bonomi A, Anderson M, Rivara F, Thompson R (2007) Health outcomes in women with physical and sexual intimate partner violence exposure. J Womens Health 16(7): 987-997.

55. Surís A, Lind L, Kashner TM, Borman PD (2007) Mental health, quality of life, and health functioning in women veterans: Differential outcomes associated with military and civilian sexual assault. J Interpers Viol 22(2): 179 -197.

56. Campbell R, Lichty LF, Sturza M, Raja S (2006) Gynecological health impact of sexual assault. Res Nurs Health 29(5): 399-413. 


\section{Psychology and Behavioral Science International Journal}

57. Steine IM, Harvey AG, Krystal JH, Milde AM, Grønli J, et al. (2012) Sleep disturbances in sexual abuse victims: A systematic review. Sleep Med $\operatorname{Rev} 16(1): 15-25$.

58. Siegel DJ (1995) Memory, trauma, and psychotherapy: A cognitive science view. J Psychother Pract Res 4(2): 93-122.

59. Yates JL, Nasby W (1993) Dissociation, affect, and network models of memory: An integrative proposal. J Trauma Stress 6(3): 305-326.

60. Elliott DM, Briere J (1995) Posttraumatic stress associated with delayed recall of sexual abuse: A general population study. J Trauma Stress 8(4): 629-648.

61. Herman JL, Schatzow E (1987) Recovery and verification of memories of childhood sexual trauma. Psychoanal Psychol 4(1): 1-14.

62. Hembroke H, Ceci S (1995) Traumatic memories: Do we need to invoke special mechanisms? Consciousness Cogn 4(1): 75-82.

63. Mechanic MB, Resick PA, Griffin MG (1998) A Comparison of Normal Forgetting, Psychopathology, and Information-Processing Models of Reported Amnesia for Recent Sexual Trauma. J Consult Clin Psycho 66(6): 948-957.

64. Clum GA, Nishith P, Resick PA (2001) Trauma-related sleep disturbance and self-reported physical health symptoms in treatment-seeking female rape victims. J Nerv Ment Dis 189(9): 618-622.

65. Campbell R, Dworkin E, Cabral G (2009) An ecological model of the impact of sexual assault on women's mental health. Trauma Violence Abuse 10(3): 225-246.

66. National Center for Victims of Crime \& Crime Victims Research and Treatment Center (1992) Rape in American: A Report to the Nation. Arlington, VA: National Center for Victims of Crime.

67. Feeny N, Foa E, Treadwell K, March J (2004) Posttraumatic stress disorder in youth: A critical review of the cognitive and behavioral treatment outcome literature. Prof Psychol Res Pr 35(5): 466-476.
68. Regehr C, Regehr G, Bradford J (1998) A model for predicting depression in victims of rape. J Am Acad Psychiatry Law 26(4): 595605 .

69. Nickerson A, Steenkamp M, Aerka IM, Salters-Pedneault K, Carper TL, et al. (2013) Prospective investigation of mental health following sexual assault. Depress Anxiety 30(5): 444-450.

70. Harvey MR (2007) Towards an Ecological Understanding of Resilience in Trauma Survivors: Implications for Theory, Research, and Practice. J Aggress Maltreat Trauma 14(1-2): 9-32.

71. Connor PK, Higgins D (2008) The "HEALTH” model. Part 1: treatment program guidelines for Complex PTSD. Sex Relation Ther 23(4): 293303.

72. Halligan SL, Michael T, Clark DM, Ehlers A (2003) Posttraumaatic stress disorder following assault: The role of cognitive processing, trauma memory, and appraisals. J Consult Clin Psychol 71(3): 419-421.

73. Koss MP, Figueredo AJ (2004) Change in Cognitive Mediators of Rape's Impact on Psychosocial Health Across 2 Years of Recovery. J Consult Clin Psychol 72(6): 1063-1072.

74. Frazier PA (2003) Perceived control and distress following sexual assault: A longitudinal test of a new model. J Pers Soc Psychol 84(6): 1257-1269.

75. Weaver TL (2009) Impact of Rape on Female Sexuality: Review of Selected Literature. Clin Obstet Gynecol 52(4): 702-711.

76. Schnurr PP, Green BL (2004) Trauma and Health: Physical Health Consequences of Exposure to Extreme Stress. Washington, DC: American Psychological Association 247-275.

\section{Your next submission with Juniper Publishers} will reach you the below assets

- Quality Editorial service

- Swift Peer Review

- Reprints availability

- E-prints Service

- Manuscript Podcast for convenient understanding

- Global attainment for your research

- Manuscript accessibility in different formats ( Pdf, E-pub, Full Text, Audio)

- Unceasing customer service

Track the below URL for one-step submission https://juniperpublishers.com/online-submission.php 